of the sky, written of course by a scientific man (one who seems to have read that silly little book by Chevreul on complementary colours), in which he suggests that as the sun looks orange, therefore the sky looks blue. He says that upon this theory the planets of Sirius and Vega must have a black sky, those of Betelgeuse a green slky, and so on. But if my readers go to the Royal Academy, some of them will probably be a little surprised to find that they are positively living on a planet which enjoys the advantage of a solid lemon-yellow sky! a sort of information not to be picked up every day: In the same sort of way, ethnological students may inform themselves that the ancient Greek heroines were shaded with streaks of treacle about their "great marbly limbs." But the judicious investigator will take note that the chief end of most of this canvas, and the purpose of most of this paint, is to indulge the artists and their disciples with reminiscences of antecedent art-an exemplification of the cud-chewing tendencies of his species. Many of them have drank deeply at the fountain of second-hand beauty; they have drank perhaps intemperately, and their speech must needs be somewhat sublime to uninstructed ears.

Let not the student carry away the impression that artistic faculties and wanton inaccuracy are necessarily connected. If the scientific writer who offered suggestions to account for the blueness of the sky had acquired the habit, which the practice of painting gives, of comparing the intervals between different colours, and estimating the intensities as well as the extent of the several elements that go to make up any given scene in the outof-doors world, he could hardly fail to notice that the sun at mid-day would in all cases be the least coloured object in the whole field of view; that the colours of other objects would neither gain nor lose perceptibly where exposed to his direct rays; whereas, the shaded and overshadowed parts of them would suffer various enhancements or modifications from the coloured rays reflected from surrounding surfaces; and that, in the case referred to, in a mid-day cloudless sky, the most widely extended and most purely coloured of all the surrounding spaces being blue, all the shadows and many of the shades would be dyed blue, so to speak, over their own proper colours; and that the whole scene would be steeped in the "blue flood of light" of the poets. The colours of the face of our planet, both native and derived, present a large field for study, and a good deal more can probably be ascertained about them than about many less pleasant yet less neglected subjects; and when the scientific investigators have done with the blue sky, I hope they will let us hear what they have to say of the blue sea.

What is the moral of all this? Simply that the scientific men pay too little attention to the broadcr aspects of the visible world ; while the artists on their part pass by the clear fountain of natural beauty, and content themselves with dreamily sipping lukewarm water from the corroded vessels of their forefathers; the one group of doers standing apart from the other; whereas, if either would go to school with the other, they would, in my opinion, each stimulate and aid the labours of the other, and divide between them a far larger shale of the spoils the vrorld.

JOHN BRETT

\section{ON THE NATURAL LAWS OF MUSCULAR} EXERTION

$A M O N G$ a multitude of profound and happy suggestions to be found in Mr. Babbage's Economy of Manufactures, are some remarks on the relation between fatigue and the rapidity or degree of muscular exertion. Coulomb, it appears, had previously investigated the most favourable load for a porter, and had ascertained by experiment that a man walking upstairs without any load, and raising his burden by means of his own weight in descencling, could do as much work in one day as four men employed in the ordinary way with the most favourable load. Mr. Babbage clearly points out (p. 30) that the exertion necessary to accomplish any kind of work consists partly of that necessary to move a limb of the bocly, and partiy of the force actually utilised in the work. The heavier the work dowe, the larger the proportion, therefore, of the power utilised. But there is a limit to this mode of increasing the useful effect, because, by the natural constitution of the muscles, they can only develop a limited amount of force in a given time, and the fatigue rapidly increases with the intensity and rapidity of exertion. Hence there is in every kind of work a point of maximum efficiency, which is in practice ascertained more or less exactly by frequent trial.

This subject appeared to me to possess interest for at least two reasons : it might be made to throw some light upon the chemical and physiological conditions of muscular force ; it might also point out how we could make some commencement, however humble, of defining the mathematical relations upon which the science of economy is founded. I have therefore attempted to add precision and certainty to the ideas put forth by Coulomb and Babbage, by some experiments of a simple kind.

The first and least interesting series of experiments consisted in ascertaining the comparative distances to which various weights could be thrown upon level ground. The product of the weight and distance was taken as the measure of useful work, and it was the object to ascertain according to what law this varied, and at what point it was a maximum. The weights employed varied from $\frac{1}{2} \mathrm{lb}$. up to $56 \mathrm{lbs}$., and were thrown as nearly as possible in a uniform manner and at the most advantageous angle. About 57 experiments at different times were made with each weight, or 456 experiments in all ; and it was quite obvious that good average results were obtained, the correspondence of different sets being very satisfactory. The results are as below :-

Weight )

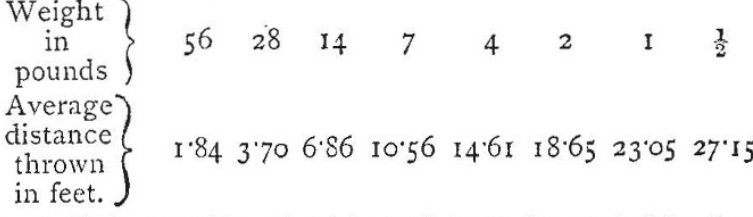

A little consideration showed it to be probable that these numbers would agree with an equation of the form-

$$
x=\frac{p}{w+q}
$$

in which $x=$ distance thrown,

$w=$ weight thrown,

$q=$ constant weight representing about half that of the arm

$p=$ constant amount of force exerted. 
The experiments give us eight distinct equations by which to determine the two unknown quantities $p$ and $q$; and by the method of least squares we determine their most probable values to be-

$$
\begin{aligned}
& \text { The formula thus becomes- } \\
& \qquad x=\frac{\mathrm{r} 15 \cdot 7}{w+3{ }^{\circ} 9}
\end{aligned}
$$

$$
\begin{aligned}
& p=\text { II5.7 } \\
& q=3.9
\end{aligned}
$$

And calculating thence the distances for the several weights, they are :-

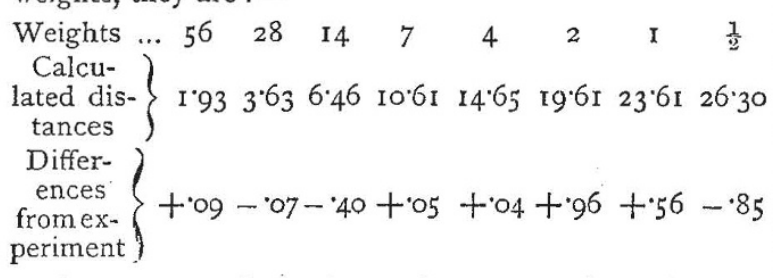

The correspondence is so close as to show that the formula is in all probability the true one, and the quantity 3.9 does not differ much from half the weight of the arm, which might be expected to enter into the question. The fact is that the correspondence is embarrassingly close, and $I$ am inclined to attribute it partly to chance. The experiments could hardly have been expected to give results accurate to an inch or two in some cases, and though the formula must be considered true on the ground of experiment, I do not quite see how to explain it on mechanical principles.

If we regard the useful effect as the moving of the greatest amount of matter, it is $x \times w$, and, theoretically

\begin{tabular}{|c|c|c|c|c|c|c|c|c|}
\hline Weight... & 56 & 28 & 14 & 7 & 4 & 2 & $I$ & $\frac{1}{2}$ \\
\hline $\left.\begin{array}{r}\text { Useful } \\
\text { effect }\end{array}\right\}$ & 108. & Ior. 6 & $90 \% 4$ & 743 & $58 \cdot 6$ & 39 & $23 \cdot 6$ & 13 \\
\hline
\end{tabular}
speaking, increases continually with $w$. For the different weights and calculated distances, it is as follows :-

But in reality it was not possible to raise the larger weights without exerting additional force unconsidered in the formula, so that the practical maximum of efficiency is probably about 281 b., in the case of my own right arm. With different people it would, of course, vary somewhat.

The above experiments completely confirmed $\mathrm{Mr}$. Babbage's remarks, but did not seem to lead to any further results. I proceeded, therefore, to other experiments upon the rate of exhaustion of muscular fibre. One mode of trial was to raise and lower various weights by a pulley and cord through the convenient range of the arm, continuing the motion with unrelaxed rapidity until the

\begin{tabular}{|c|c|c|c|c|c|}
\hline Weight lifted ... & 56 & 42 & 28 & $2 \mathrm{I}$ & 14 \\
\hline $\left.\begin{array}{c}\text { Average } \\
\text { number of }\end{array}\right\}$ & 57 & I I'9 & $23^{\circ} \mathrm{O}$ & $37 \cdot 6$ & IIIOO \\
\hline $\left.\begin{array}{c}\text { number of } \\
\text { times }\end{array}\right\}$ & 57 & 119 & & ग) & 120 \\
\hline
\end{tabular}
power of the muscles was entirely exhausted. The results of more than fifty experiments were as follows :-

$\begin{array}{llllll}\text { Useful effect } \ldots & \text { 319 } & 500 & 644 & 790 & 1554\end{array}$

These numbers show that the total greatest amount of labour can be done with small rather than large weights in this case; but they fail to give any regular law, owing probably to the weight of the body being brought into use with the larger weights.

The mode ultimately adopted was to hold out various weights in the hand at the full stretch of the arm, and to observe the times during which they could be supported. No two experiments were made with the same arm, without allowing, at least, one hour to elapse, so that the vigour of the muscles might be restored. With the smaller weights there was naturally some uncertainty as to the time, but in the case of the large ones the time was very definite. Altogether 238 experiments were made, an equal number with each arm. Uniting all the experiments for the same weight, the results are :-

$\begin{array}{ccccccccc}\text { Weight } & \ldots & \text { I } 8 & \text { I4 } & \text { 10 } & 7 & 4 & 2 & \text { I } \\ \left.\begin{array}{r}\text { Times in } \\ \text { seconds }\end{array}\right\} & 14.8 & 32.5 & 60.3 & 87.4 & 147.9 & 218.9 & 32 \text { I.2 }\end{array}$

These results are pretty satisfactory averages; thus the probable error, for two cases indifferently chosen, was, for I8lbs. in the left hand about '5, and for 4 lbs. in the right 27 , and the error of the combined results would be less. With the exception of the results for Iolbs. in the left arm, which appear to be somewhat in excess, these numbers are very regular, and point to a systematic law governing the rate of fatigue. The useful effect, or the product of the weight and time, shows a decided maximum, about $7 \mathrm{lbs}$, as follows :-

$\begin{array}{lrrrrrrr}\text { Weight } & \text { I8 } & \text { I4 } & \text { 10 } & 7 & 4 & 2 & \text { I } \\ \text { Useful effect } & 266 & 455 & 603 & 612 & 592 & 438 & 32 \text { I }\end{array}$

If the weight held be very small, much power is lost in merely sustaining the arm; if the weight is large, there is comparatively little loss on that account, but the power of the muscles is soon run out, and no sufficient opportunity for restoration is allowed. The weights chosen for dumb-bells and other gymnastic exercises appear to be about those which give the maximum efficiency.

I have made several attempts to explain these numbers by reasonable suppositions as to the conditions of exhaustion and restoration of muscular power. It seemed reasonable to suppose that the supply of new matter from the blood would increase in some proportion to the vacancy or want of it, but all such conditions led to integrals of a logarithmic form, which could not be easily compared with experimental results. No formula that I obtained could be made to agree properly with the figures, and all that can be said is that the curve representing the results has a certain appearance of a logarithmic character, so far agreeing with the formulas obtained. Those who are acquainted with the physiology of the subject might succeed better; I am not sure, for instance, how far the failure of strength is due to the exhaustion of the original substance of the muscle, how far to the inadequacy of the current supply of blood. It is a question again how far in any case of muscular action the supply is promoted by the increased action of the heart, or checked by the possible constriction of the arteries. If these questions have not been or cannot be otherwise decided, they might, perhaps, be indirectly solved by experiments of the kind described.

My own object, however, was not to intrude into the domain of physiology, but to show that definiteness might possibly be given by degrees to some of the principles and laws which form the basis of the science of political economy. In some speculations upon the mathematical theory which must underlie that science (read at the British Association in 1862 , and published in the Journal 
of the Statistical Society for June I866, p. 282), I endeavoured to show that it was only the excessive difficulty of determining the character of the functions involved, which prevented economy from taking the mathematical form and standing proper to it. There is little doubt as to the principles of the subject; but when we try to put them into figures, the data are found to be so deficient, complicated, variable, and subject to disturbances of all kinds, that any hope of accuracy soon dies away in most cases. In the above experiments I have attempted to determine the exact character of the functions connecting the arnount of work done with the intensity and duration of labour in certain simple cases. These cases, however unimportant in themselves, represent principles which have innumerable applications in common life.

\section{W. Stanley Jevons}

\section{THE NEW ZEALAND INSTITUTE}

Transactions and Proceedings of the Ner Zealand Institute, I868. Vol I. Edited and published under the authority of the Board of Governors of the Institute, by James Hector, M.D., F.R.S., Wellington. (London : Trübner and Co.)

UR brother philosophers at the Antipodes have set us an example that we should do well to follow in this country; those who reside at head-quarters (Wellington) and who form the New Zealand Institute, having affiliated to themselves under a special Act of the Legislative Government, the various other societies engaged in similar pursuits that exist in the New Zealand Islands; and who in consequence transmit their papers, or abstracts of them, to the Institute for incorporation in their Transactions. It is to such an organisation as this that we must look for relief from the overwhelming pressure of miscellaneous scientific literature under which the British naturalist now groans. No matter what branch of science he affects, or in how narrow a groove of it he walks, the number of Transactions, Proceedings, Journals, \&c., with which he must keep au courant, is the great obstacle to his progress; and if he at all takes a broad view of his science, he must be content that it should be a superficial one, and increasingly so as new societies and journals spring into being.

The rules and statutes of the New Zealand Institute appear to be under parliamentary control, and have little analogy with the charters of our free-born societies:-they were published in the New Zealand Gazette of March 9, 1868, and the following is a summary of them :-

Art. I. Any society desirous of incorporation must consist of twenty-five or more members, and subscribe $50 l$. annually for the promotion of the branch of knowledge it professes.

Art. 2. Incorporation ceases on the failure of these conditions.

Art. 3. Any such society must expend either one-third of its annual revenues in or towards the support of a local library or museum, or one-sixth of its revenues to the extension and maintenance of the museum and library of the Institute.

Art. 4. Failure of this condition is followed by cessation of incorporation.

Art. 5. All papers read at such societies shall be re- garded as communications to the Institute, and be published by it, under the following regulations :-

(a) The publication shall consist of a current abstract of the proceedings of the incorporated societies, and of papers read before them; and shall be entitled "Transactions of the New Zealand Institute."

(b) The Institute has the power to reject papers, but (c) must return them. (d) A proportional contribution for the cost of publishing the Transactions may be demanded of the societies in respect of the papers they contribute; and $(e)$ a proportional number of copies of the Transactions will be sent to each society; which may also $(f)$ have as many copies as it pleases, at cost price.

Art. 6. Funds and properties derived from the societies shall be vested in the Institute, and applied by its governors to public uses.

Art. 7. The incorporated societies shall conduct their own affairs, making their own bye-laws, \&c.

Art. 8. Certificates of incorporation are granted upon application and compliance with the foregoing conditions, under the seal of the Institute.

The museum and library of the Institute are under the management of the Board of Governors; the laboratory is under the exclusive management of the manager of the Institute.

The governors are nine in number: the official ones are the Governor of the Colony, the Colonial Secretary, and the Superintendent of Wellington; joined to six men, eminent for their scientific attainments or love of science; amongst whom are Dr. Hector, who is likewise manager, and the Hon. Col. Haultain, who is likewise hon. secretary and treasurer. There are four affiliated societies: the Wellington Philosophical Society, the Auckland Institute, the Philosophical Institute of Canterbury, and the Westland Naturalists' and Acclimatisation Society.

With regard to the contents of this first volume, it opens with a capital purpose-like address from the Governor, Sir. G. Bowen, which is followed by a series of papers, for the most part of very great scientific value and interest, and which give a very favourable idea indeed of the spread of scientific knowledge in the Colony, and the number of earnest workers it contains.

Of these, those comprising the Transactions contain no fewer than twenty-two articles on Geology, Physics, Botany, Ornithology, Applied Sciences, Wave and Earthquake pheriomena, \&c.; these are followed by thirty-nine papers and verbal descriptions of scientific phenomena; and these again by ten essays of great research and merit, respectively entitled :-

"On the Geographical Botany of New Zealand," "On the Leading Features of the Geographical Botany of the Provinces of Nelson and Marlborough," "Remarks on a Comparison of the General Features of the Flora of the Provinces of Nelson and Marlborough, with that of Canterbury," "Sketch of the Botany of Otago," "On the Ornithology of New Zealand," "On the Botany, Geographic and Economic, of the North Island of New Zealand," "On the Cultivation and Acclimatisation of Trees and Plants," "On the Geology of the North Island of New Zealand," "Short sketch of the Maori Races," "On the Maori Races."

The last of these is the result of the life-long labours of one of the most accomplished and industrious of the early missionary settlers in the North Island, Mr. Colenso ; whose botanical researches have been as important as his 